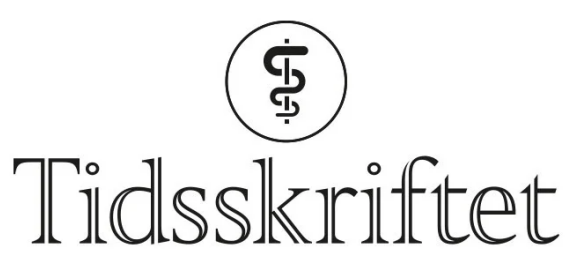

DEN NORSKE LEGEFORENING

\title{
Pasienter nyretransplantert ved Ullevål sykehus 1963-83
}

ORIGINALARTIKKEL

\section{SARA NAMEK}

Oslo universitetssykehus, Ullevål sykehus

Hun har bidratt med datainnsamling, analyse av data, litteraturs $\emptyset \mathrm{k}$ og utarbeiding og godkjenning av innsendt manus.

Sara Namek er lege i spesialisering i kirurgi i Danmark. Hun er tidligere LIS1-lege ved Ullevål sykehus. Forfatteren har fylt ut ICMJE-skjemaet og oppgir ingen interessekonflikter.

\section{TORE SCHWEDER}

$\emptyset$ konomisk institutt

Det samfunnsvitenskapelige fakultet

Universitetet i Oslo

Han har bidratt med analyse av data, med ansvar for statisk beregning, og godkjenning av innsendt manus.

Tore Schweder er professor emeritus i statistikk.

Forfatteren har fylt ut ICMJE-skjemaet og oppgir ingen interessekonflikter.

\section{MONS LIE}

mons.lie@online.no

Oslo universitetssykehus, Ullevål sykehus

Han har bidratt med idé, utforming og design, analyse og tolkning av data, litteratursøk og

utarbeiding av manus.

Mons Lie er pensjonert spesialist i karkirurgi og torakskirurgi. Han er tidligere

transplantasjonskirurg ved Kirurgisk avdeling III, avdelingsoverlege ved Torakskirurgisk avdeling og direktør ved Hjerte-lunge-senteret ved Ullevål sykehus.

Forfatteren har fylt ut ICMJE-skjemaet og oppgir ingen interessekonflikter.

\section{BAKGRUNN}

Fra november 1963 til juli 1983 ble 118 pasienter nyretransplantert ved Ullevål sykehus. Etter dette ble virksomheten flyttet til Rikshospitalet. Hensikten med vår undersøkelse er å presentere demografiske data og pasient- og graftoverlevelse fra den første pasientkohorten av nyretransplanterte i Norge.

\section{MATERIALE OG METODE}

Pasientene ble identifisert i operasjonsprotokoller fra Ullevål sykehus og Norsk nyreregister med oppfølgingsdata frem til desember 2016. Vi kartla alder og kjønn, årsak til nyresvikt, donorkarakteristika, pasient- og graftoverlevelse, antall retransplantasjoner og dødsårsak for pasientene. 


\section{RESULTATER}

118 pasienter, 38 kvinner og 80 menn, i alderen $14-67$ år ble transplantert i perioden. De vanligste årsakene til transplantasjon var kronisk glomerulonefritt $(n=61)$, kronisk pyelonefritt $(n=20)$ og polycystisk nyresykdom $(n=14) .72$ pasienter $(61 \%)$ fikk nyre fra avdød donor. Etter ett år levde 94 av pasientene (8o \%), etter fem år 66 av pasientene (56\%) og etter tjue år 34 av pasientene (29\%). Kardiovaskulær sykdom var hyppigste dødsårsak. Median graftoverlevelse var 3,8 år (kvartilbredde 14,4 år). 32 pasienter ble retransplantert.

FORTOLKNING

Allerede i denne pionertiden var pasientoverlevelsen og funksjonstiden for nyretransplantat akseptabel.

\section{HOVEDFUNN}

Av 118 pasienter som ble nyretransplantert ved Ullevål sykehus i perioden 1963-83, fikk 61 \% nyre fra avdød donor.

$29 \%$ av pasientene levde fortsatt etter 20 år.

Median graftoverlevelse var 3,8 år.

Kardiovaskulær sykdom var hyppigste dødsårsak.

Den første vellykkede nyretransplantasjonen i Norge ble utført på Ullevål sykehus 5. november 1963 (1). Pasienten, en 35 år gammel mann, levde i 22 år etter operasjonen med nyren han fikk fra moren. Operasjonen fant sted ni år etter verdens første vellykkede nyretransplantasjon (므). Den første hemodialyseavdelingen på Ullevål sykehus ble opprettet i 1969. Før den tid ble alle pasientene hemodialysert på Institutt for eksperimentell medisinsk forskning, også på Ullevål sykehus, der Fredrik Kiil og Bjørn Amundsen hadde utviklet Kiil-nyren, med første vellykkede hemodialyse i 1959. I 1969 ble det inngått et nordisk samarbeid om utveksling av organer til transplantasjon kalt Scandiatransplant (3). Samme år startet et nasjonalt program i Norge med tilbud om nyretransplantasjon til alle nyresviktpasienter som kunne ha nytte av det, der Ullevål sykehus og Rikshospitalet dekket hver sin del av landet. Av stor betydning for transplantasjonsmedisinen var oppdagelsen av azatioprin som immunsuppressivt middel i 1963. Videre ble i 1983 ciklosporin tatt i bruk som immunsuppressivt medikament, hvilket førte til en betydelig $ø$ kning i organtransplantasjoner verden over. På dette tidspunktet ble det inngått avtale mellom Ullevål sykehus og Rikshospitalet om at all organtransplantasjon i Norge skulle utføres på Rikshospitalet i Oslo (4.).

I 1992 publiserte Gorlén og medarbeidere en rapport om de 69 første pasientene som ble nyretransplantert ved Ullevål sykehus fra 1963 til begynnelsen av 1978 (5). I denne retrospektive studien har vi i tillegg inkludert pasienter operert frem til juli 1983, og observasjonen av de opererte pasientene varte frem til desember 2016.

Vi har kartlagt alder og kjønn, pasient- og graftoverlevelse etter transplantasjon med nyre fra levende versus avdød donor, antall retransplantasjoner, årsak til nyresvikt og pasientenes dødsårsak.

\section{Materiale og metode}

Denne rapporten er en retrospektiv beskrivende studie av de 118 pasientene som ble transplantert ved Ullevål sykehus i perioden fra november 1963 til juli 1983. Pasientene ble identifisert ut fra håndskrevne operasjonsprotokoller ved Kirurgisk avdeling III, Ullevål 
sykehus, og fra Norsk nyreregister, som ble dannet i 2016 ved sammenslåing av Norsk nefrologiregister og Norsk nyrebiopsiregister. Journalene til pasientene ble samlet inn fra sykehusarkivene.

Postoperativt fikk alle prednisolonbehandling (7,5-10 mg daglig) og azatioprin 1-1,5 mg per $\mathrm{kg}$ kroppsvekt daglig som immunsuppresjon. Vi har ikke full oversikt over immunsuppresjonsbehandlingen disse pasientene fikk etter at Rikshospitalet overtok all organtransplantasjon og en vesentlig del av pasientoppfølgingen i 1983. Data om retransplantasjoner, donorstatus og eventuell graftsvikt er hentet fra Norsk nyreregister. Folkeregisteret er benyttet for fastsettelse av dødstidspunkt. Dødsårsaker er hentet fra pasientjournaler.

Vi registrerte pasientoverlevelse ett, fem og tjue år etter transplantasjon. Graftoverlevelse er definert som tid til retransplantasjon eller $\mathrm{d} ø \mathrm{~d}$ forårsaket av nyresvikt og basert på opplysninger fra pasientjournal.

Endepunktet for observasjonen var enten pasientens død eller 1. desember 2016, da studien ble avsluttet.

\section{STATISTIKK}

Deskriptive data er angitt som median og kvartilbredde.

ETIKK

Studien er godkjent av Personvernombudet ved Oslo universitetssykehus og vurdert som ikke meldepliktig til Regionale komiteer for medisinsk og helsefaglig forskningsetikk (REK).

\section{Resultater}

Totalt 118 pasienter, 38 kvinner og 80 menn, i alderen $14-67$ år på operasjonstidspunktet ble transplantert i perioden (figur 1 ). Alle hadde terminal nyresvikt og var i hemodialyse. Operasjonsfrekvensen var økende fra én til to pasienter i året i 196o-årene til over ti i året i slutten av 1970-årene.

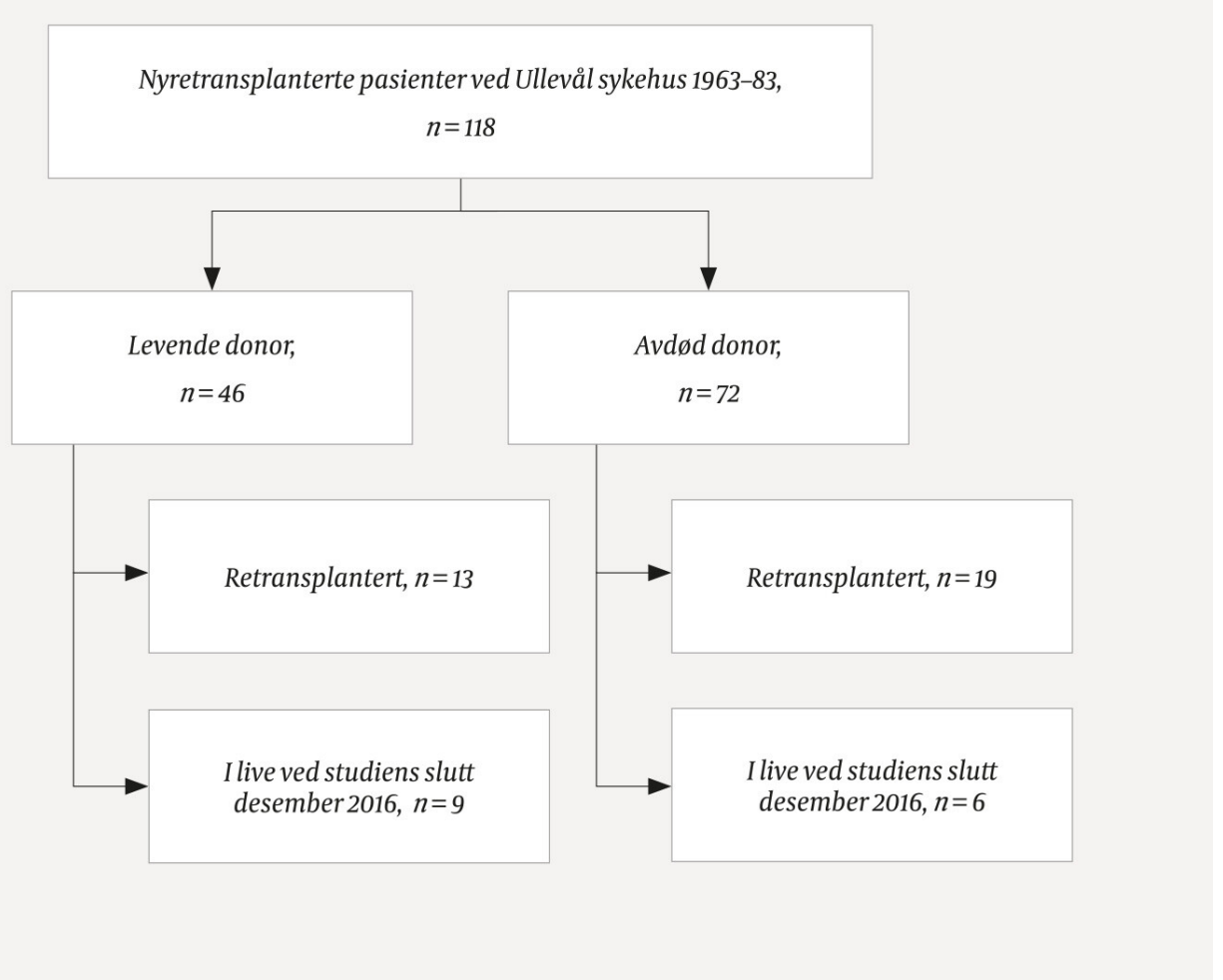

Figur 1 Pasienter i studien. 
Årsaken til nyresvikt var kronisk glomerulonefritt hos 61 pasienter, kronisk pyelonefritt hos 20, polycystisk nyresykdom hos 14, nefrosklerose hos 5 og medfødt nefritt hos 2 . Hos 16 pasienter hadde nyresvikten andre årsaker.

46 pasienter (39\%) fikk nyre fra en levende donor (tabell 1). 13 av dem ble senere retransplantert. 3 fikk da nyre fra levende donor, resten fikk transplantater fra avdød donor.

\section{Tabell 1}

Nyretransplanterte pasienter ved Ullevål sykehus 1963-83. Pasientkarakteristika og graftoverlevelse etter nyretransplantat fra levende eller avdød donor. Tallene viser antall (\%) dersom ikke annet er oppgitt.

\begin{tabular}{|llcr|}
\hline & Levende donor & Avdød donor & Totalt \\
\hline Antall pasienter (kvinner) & $46(15)$ & $72(23)$ & $118(38)$ \\
\hline $\begin{array}{l}\text { Median pasientalder, år } \\
\text { (kvartilbredde) }\end{array}$ & $32(20)$ & $50(19)$ & $42(23)$ \\
\hline $\begin{array}{l}\text { Median donoralder, år } \\
\text { (kvartilbredde) }\end{array}$ & $52(16)$ & $39(30)$ & $44(26)$ \\
\hline Antall retransplanterte & $13(28)$ & $19(26)$ & $32(27)$ \\
\hline Ettårsoverlevelse, pasienter & $43(93)$ & $51(71)$ & $94(80)$ \\
\hline Femårsoverlevelse, pasienter & $36(78)$ & $30(41)$ & $66(56)$ \\
\hline Tjueeårsoverlevelse, pasienter & $20(43)$ & $14(19)$ & $34(29)$ \\
\hline $\begin{array}{l}\text { Median pasientoverlevelse, år } \\
\text { (kvartilbredde) }\end{array}$ & $14(30)$ & $4(13)$ & $7(23)$ \\
\hline $\begin{array}{l}\text { Median graftoverlevelse, år } \\
\text { (kvartilbredde) }\end{array}$ & $12(27)$ & $2(7)$ & $4(14)$ \\
\hline
\end{tabular}

72 pasienter (61\%) fikk transplantat fra avdød donor (tabell 1). 19 av disse ble senere retransplantert med nyre fra avdød donor.

Blant de totalt 32 pasientene som ble retransplantert i perioden, fikk 22 utført én retransplantasjon og 10 utført to retransplantasjoner, dvs. det ble utført totalt 16o transplantasjoner på de 118 pasientene.

Median overlevelse for transplantatet var 12,4 år (kvartilbredde 26,9 år) ved levende nyredonor og 1,8 år (kvartilbredde 6,7 år) ved avdød donor.

Median overlevelse for pasientene var 14 år (kvartilbredde 30 år) ved bruk av levende donor og 4 år (kvartilbredde 13 år) ved bruk av avdød donor. Median overlevelse etter alder ved operasjon i femårige aldersgrupper var sammenliknbar mellom pasienter som fikk nyre fra levende donor, og pasienter som fikk nyre fra avdød donor (data ikke vist).

Ved studiens avslutning var femten pasienter fremdeles i live, med en median observasjonstid på 41,4 år. Av disse hadde ni opprinnelig fått transplantat fra levende donor, hvorav fem senere var blitt retransplantert, mens fire fortsatt hadde fungerende opprinnelig transplantat. Seks av de overlevende hadde opprinnelig fått transplantat fra avdød donor. Tre av disse var blitt retransplantert, mens tre hadde den opprinnelig transplanterte nyren i funksjon.

Hovedårsakene til død i kohorten var hjerte- og karsykdommer og hjerneslag, sepsis, lungebetennelse og kreft (tabell 2). 


\section{Tabell 2}

Dødsårsaker blant nyretransplanterte ved Ullevål sykehus 1963-83 som var døde ved studiens avslutning i $2016(n=103)$. Basert på informasjon i pasientjournaler.

\begin{tabular}{|lr|}
\hline Dødsårsak & Antall pasienter \\
\hline Kardiovaskulær sykdom & 28 \\
\hline Kreft & 14 \\
\hline Sepsis & 14 \\
\hline Slag & 10 \\
\hline Pneumoni & 8 \\
\hline Andre årsaker & 20 \\
\hline Ukjent & 9 \\
\hline Totalt & 103 \\
\hline
\end{tabular}

\section{Diskusjon}

De 118 pasientene transplantert ved Ullevål sykehus fra 1963 til 1983 representerer en pionerperiode i organtransplantasjonens historie, før registreringen av ciklosporin i 1983 gjorde organtransplantasjon til et akseptert behandlingstilbud over hele verden. I november 1963, da den første pasienten med langtidsoverlevelse ble transplantert i Norge, var det rapportert om svært få allotransplantasjoner med mer enn noen måneders overlevelse i Europa.

Ifølge Norsk nyreregister er median graftoverlevelse de siste årene 12 år ved nyretransplantat fra død donor og 15 år ved nyretransplantat fra levende donor. $\emptyset \mathrm{kt}$ graftoverlevelse i forhold til tidligere skyldes i vesentlig grad bruk av kalsineurinhemmerne ciklosporin og takrolimus. Det er bemerkelsesverdig at begge donortyper er representert blant pasientene som fortsatt hadde sin opprinnelig transplanterte nyre i funksjon ved studiens avslutning etter en median observasjonstid på 41,4 år.

Noen studier har funnet at nyre donert fra levende donor er assosiert med høyere pasientoverlevelse enn nyre fra avdød donor (5, 6-9.), mens andre ikke har funnet noen sammenheng mellom pasientoverlevelse og donors status $(\underline{2}, \underline{10}, \underline{11})$. Gorlén og medarbeideres studie av de 69 første nyretransplanterte pasientene ved Ullevål sykehus viste at pasienter med nyre fra avdød donor hadde høyere dødelighet enn pasienter med nyre fra levende donor (5). I vårt materiale fant vi også høyere median overlevelse blant pasienter som fikk nyre fra levende donor, men disse pasientene var gjennomgående yngre enn de som fikk transplantat fra avdød donor, noe som kan forklare deres høyere overlevelse. For pasienter innen samme femårige aldersgruppe ved operasjon ser medianoverlevelsen ut til å være omtrent den samme enten donor var levende eller avdød (data ikke vist). Vi har imidlertid, i motsetning til Gorlén og medarbeidere, ikke korrigert for andre variabler som kan påvirke overlevelse, slik som donors alder, tid i dialyse eller HLA-uforlikelighet. 
Gorlén og medarbeideres studie av delvis samme pasientkohort viste $55 \%$ og $44 \%$ gjennomsnittlig overlevelse etter henholdsvis 10 og 20 år (5). Vi fant en samlet median overlevelsesrate etter 10 og 20 år på henholdsvis $45 \%$ og $29 \%$ (data ikke vist i resultatdel for 10 år). Pasientene i vårt materiale var imidlertid gjennomgående eldre enn pasientene i den først publiserte rapporten.

Pasientoverlevelsen i vår studie er sammenlignbar med funnene i Henari og medarbeideres studie fra $1977(\underline{10})$, hvor langtidshemodialyse ble sammenlignet med nyretransplantasjon hos 200 pasienter, og Bradley og medarbeideres studie som rapporterte langvarig overlevelse hos 177 pasienter som fikk nyrerstatningsterapi i form av hemodialyse og ikke

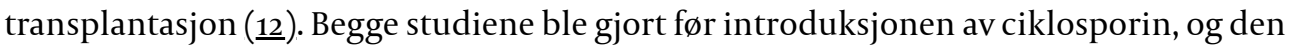
første differensierte ikke mellom pasienter som fikk transplantat fra levende donor, og pasienter som fikk fra avdød donor.

Årsaken til nyresvikt var oppgitt i journalen som kliniske diagnoser, ikke biopsiverifisert, med kronisk glomerulonefritt, kronisk pyelonefritt og polycystisk nyresykdom som de tre hyppigst forekommende. Pasienter med diabetes, som er en av de hyppigste grunnliggende lidelsene blant dagens nyresviktpasienter, var ekskludert fra dette tidlige behandlingstilbudet.

Hos de fleste i studien var arteriosklerose med hjerte- og karsykdommer og hjerneslag registrert som dødsårsak. Den nest vanligste årsaken var infeksjoner med sepsis og lungebetennelse. At infeksjoner har relasjon til immunsuppresjon er sannsynlig. Disse funnene er i samsvar med andre rapporter $(\underline{2}, \underline{13})$. Malignitet som dødsårsak var noe hyppigere enn det som oppgis i sammenlignbare studier. Forklaringen er sannsynligvis den lange observasjonstiden og at pasientene er fulgt til høy alder.

En svakhet ved studien er at ikke alle relevante data ble samlet inn. Vi har ikke registrert hvor mye og hva slags immunsuppresjon pasientene ble gitt etter 1983. Slike data hadde vært interessante å ha med i studien. Vi har heller ikke kontaktet de overlevende pasientene ved undersøkelsens slutt for å registrere deres subjektive vurdering av livskvalitet etter transplantasjonen. Vi har brukt data angitt i pasientjournalen og er klar over at disse ikke alltid er kvalitetssikret.

Undersøkelsens styrke er den komplette registreringen av de første 118 pasientene transplantert på Ullevål sykehus etter november 1963 med hensyn til pasient- og nyreoverlevelse med oppfølging i over 40 år.

Vår konklusjon er at resultatene fra Ullevål sykehus er sammenlignbare med rapporter fra andre transplantasjonssentre i samme tidsperiode. Pasientoverlevelse og graftfunksjon må kunne anses som tilfredsstillende i forhold til datidens behandlingsmuligheter. Noen av pasientene hadde fortsatt et fungerende transplantat ved studieslutt. Den observerte forskjellen i pasientoverlevelse ved levende versus avdød donor tror vi for en stor del skyldes forskjeller i pasientenes alder. Selv om vi ikke undersøkte pasientenes livskvalitet, må vi kunne anta at en stor del av dem fikk en bedret livskvalitet som følge av transplantasjonen, ikke minst fordi behandlingsalternativet hemodialyse var klart mer belastende på denne tiden enn det senere ble.

Forfatterne takker Maria Tønne, Cecilie Lintoft og Iben Hansen for hjelp med innsamlingen av dataene og Torbjørn Leivestad for hans bidrag til oppfølgingsdata fra Norsk nyreregister.

Artikkelen erfagfellevurdert.

\section{REFERENCES}

1. Enger E, Bergan F, Hoeg K et al. Nyretransplantasjoner ved Ullevål sykehus. Et 7 års materiale. Tidsskr Nor Lægeforen 1971; 91: 1113-31. [PubMed]

2. Murray JE, Tilney NL, Wilson RE. Renal transplantation: a twenty-five year experience. Ann Surg 1976; 184: 565-73. [PubMed][CrossRef] 
4. Thorsby E. Norsk transplantasjonsmedisin gjennom 50 år. Tidsskr Nor Lægeforen 2006; 126:330510. [PubMed]

5. Gorlén T, Abdelnoor M, Enger E et al. Long term morbidity and mortality after kidney transplantation. Scand J Urol Nephrol 1992; 26:397-401. [PubMed][CrossRef]

6. The ninth report of the Human Renal Transplant Registry. JAMA 1972; 220: 253-6o. [PubMed] [CrossRef]

7. Lowrie EG, Lazarus JM, Mocelin AJ et al. Survival of patients undergoing chronic hemodialysis and renal transplantation. N Engl J Med 1973; 288: 863-7. [PubMed][CrossRef]

8. Nylander WA, Bentley FR, Najarian JS. Fifteen- to twenty-year follow-up of renal transplants performed in the 1960s. Transplant Proc 1985; 17:104-5.

9. Ehrich JH, Rizzoni G, Brunner FP et al. Combined report on regular dialysis and transplantation of children in Europe, 1989. Nephrol Dial Transplant 1991; 6 (Suppl 1):37-47. [PubMed]

10. Henari FZ, Gower PE, Curtis JR et al. Survival in 200 patients treated by haemodialysis and renal transplantation. BMJ 1977; 1: 409-12. [PubMed][CrossRef]

11. Tonelli M, Wiebe N, Knoll G et al. Systematic review: kidney transplantation compared with dialysis in clinically relevant outcomes. Am J Transplant 2011; 11: 2093-109. [PubMed][CrossRef]

12. Bradley JR, Evans DB, Calne RY. Long-term survival in haemodialysis patients. Lancet 1987; 1: 295-6. [PubMed][CrossRef]

13. Frisk B, Persson H, Wedel N et al. Study of 172 patients at 10 to 21 years after renal transplantation. Transplant Proc 1987; 19:3769-71. [PubMed]

Publisert: 13. desember 2021. Tidsskr Nor Legeforen. DOI: 10.4045/tidsskr.20.0579

Mottatt 4.7.2020, første revisjon innsendt 14.1.2021, godkjent 28.10.2O21.

Publisert under åpen tilgang CC BY-ND. Lastet ned fra tidsskriftet.no 26. april 2023. 